Address correspondence to: Alfredo Fusco, Dipartimento di Biologia e Patologia Cellulare e Molecolare c/o Istituto di Endocrinologia ed Oncologia Sperimentale del CNR, Facoltà di Medicina e Chirurgia di Napoli, Università degli Studi di Napoli "Federico II," via Pansini, 5, 80131 Naples, Italy. Phone: 0039-0813722857; Fax: 00390817463749; E-mail: afusco@napoli.com.

1. Williams, D. 2002. Cancer after nuclear fallout: lessons from the Chernobyl accident. Nat. Rev. Cancer. 2:543-549.

2. Ciampi, R., et al. 2005. Oncogenic AKAP9-BRAF fusion is a novel mechanism of MAPK pathway activation in thyroid cancer. J. Clin. Invest. 115:94-101. doi:10.1172/JCI200523237.

3. Dibb, N.J., Dilworth, S.M., and Mol, C.D. 2004 Switching on kinases: oncogenic activation of BRAF and the PDGFR family. Nat. Rev. Cancer. 4:718-727.

4. Grieco, M., et al. 1990. PTC is a novel rearranged form of the ret proto-oncogene and is frequently detected in vivo in human thyroid papillary carcinomas. Cell. 60:557-563.

5. Santoro, M., et al. 1994. Molecular characterization of RET/PTC3; a novel rearranged version of the RETproto-oncogene in a human thyroid papillary carcinoma. Oncogene. 9:509-516.

6. Pierotti, M.A. 2001. Chromosomal rearrangements in thyroid carcinomas: a recombination or death dilemma. Cancer Lett. 166:1-7.

7. Alberti, L., Carniti, C., Miranda, C., Roccato, E., and Pierotti, M.A. 2003. RET and NTRK1 proto-oncogenes in human diseases. J. Cell. Physiol. 195:168-186.

8. Futreal, P.A., et al. 2004. A census of human cancer genes. Nat. Rev. Cancer. 4:177-183.

9. Kroll, T.G., et al. 2000. PAX8-PPARgamma1 fusion oncogene in human thyroid carcinoma. Science. 289:1357-1360.

10. Fagin, J.A. 2004. Challenging dogma in thyroid cancer molecular genetics - role of RET/PTC and BRAF in tumor initiation. J. Clin. Endocrinol. Metab. 89:4264-4266

11. Nikiforova, M.N., et al. 2000. Proximity of chromosomal loci that participate in radiation-induced rearrangements in human cells. Science. 290:138-141.

12. Yang, T., et al. 1997. p53 induced by ionizing radiation mediates DNA end-jointing activity, but not apoptosis of thyroid cells. Oncogene. 14:1511-1519.

13. Kimura, E.T., et al. 2003. High prevalence of BRAF mutations in thyroid cancer: genetic evidence for constitutive activation of the RET/PTC-RAS-BRAF signaling pathway in papillary thyroid carcinoma. Cancer Res. 63:1454-1457.

14. Lima, J., et al. 2004. BRAF mutations are not a major event in post-Chernobyl childhood thyroid carcinomas. J. Clin. Endocrinol. Metab. 89:4267-4271.

15. Kumagai, A., et al. 2004. Low frequency of BRAFT1796A mutations in childhood thyroid carcinomas. J. Clin. Endocrinol. Metab. 89:4280-4284.

16. Nikiforova, M.N., et al. 2004. Low prevalence of BRAF mutations in radiation-induced thyroid tumors in contrast to sporadic papillary carcinomas. Cancer Lett. 209:1-6.

17. Bongarzone, I., et al. 1993. Molecular characterization of a thyroid tumor-specific transforming sequence formed by the fusion of ret tyrosine kinase and the regulatory subunit RI alpha of cyclic AMP-dependent protein kinase A. Mol. Cell. Biol. 13:358-366.

18. Kirschner, L.S., et al. 2000. Mutations of the gene encoding the protein kinase A type I-alpha regulatory subunit in patients with the Carney complex. Nat. Genet. 26:89-92.

\title{
The promise of stem cells in Parkinson disease
}

\section{J. William Langston}

Parkinson's Institute, Sunnyvale, California, USA.

\begin{abstract}
Neurotransplantation as a treatment for Parkinson disease reached the stage of human trials over 15 years ago, but the field, which is still in its infancy, has encountered a number of roadblocks since then, both political and scientific. With hope that stem cells may be used as a new source of dopaminergic neurons to replace the degenerating nerve cells in Parkinson disease looming, it is critical that we learn from the past as we work toward achieving new milestones aimed at making this new therapeutic strategy a reality. One of those milestones, which is an important translational step in the development of stem cell technology and the subject of a report in this issue of the $J C I$, involves transplanting new dopaminergic cell lines to a primate model of Parkinson disease (see the related article beginning on page 102).
\end{abstract}

The possibility of repairing the damaged human brain has been a dream of physicians and scientists for decades. Over time it has become obvious that Parkinson disease is a natural first when it comes to tackling this ambitious feat, primarily because the majority of the signs and symptoms appear to result from the progressive loss of cells in a small area known as the substantia nigra, which sits atop the brain stem. These cells make dopamine, which is delivered to a part of the basal ganglia known as the striatum; when nigral neurons die and striatal

Nonstandard abbreviations used: DA, dopaminergic.

Conflict of interest: The author has declared that no conflict of interest exists.

Citation for this article: J. Clin. Invest. 115:23-25 (2005). doi:10.1172/JCI200524012. dopamine diminishes, the signs and symptoms of Parkinson disease become manifest. Thus, replenishing missing neurons in a limited area of the brain should in theory reverse parkinsonism, making this an attractive approach. But the challenge of actually replacing injured and/or lost neurons in the adult human nervous system has proven to be a daunting task with far more bumps in the road, both political and scientific, than anyone would have anticipated.

\section{Neurotransplantation: trials and tribulations}

While stem cell therapy is very much in the forefront when approaches to brain repair and cell replacement therapy are being considered, there is already a substantial body of work in the Parkinson disease field involving neurotransplantation, including the use of both adult adrenomedullary tissue and human fetal mesencephalic tissue (which is rich in dopaminergic [DA] neurons); the lessons learned should not be ignored. While adrenomedullary transplantation proved to be something of a medical fiasco, with little efficacy and unacceptable morbidity and mortality, a number of the early open label trials with human fetal mesencephalic tissue appeared to be very promising. However, due to a ban on the use of federal funds for research utilizing human fetal tissue imposed by then-President Ronald Reagan, little work was done in this area until President Bill Clinton lifted this moratorium on his second day in office. Not long thereafter, 2 large controlled clinical trials aimed at using fetal human mesencephalic tissue transplanted to the striatum to treat Parkinson disease were launched with federal funding. However, to the surprise of many, both trials failed to show a significant clinical benefit based on their primary endpoint variables $(1,2)$ in spite of substantial evidence of graft survival based on both autopsy (3) and imaging studies. Unfortunately, a substantial subset of patients also developed persistent excessive movements known as dyskinesias (2). Dyskinesias are typically a consequence of long-term L-dopa therapy, but in the patients 


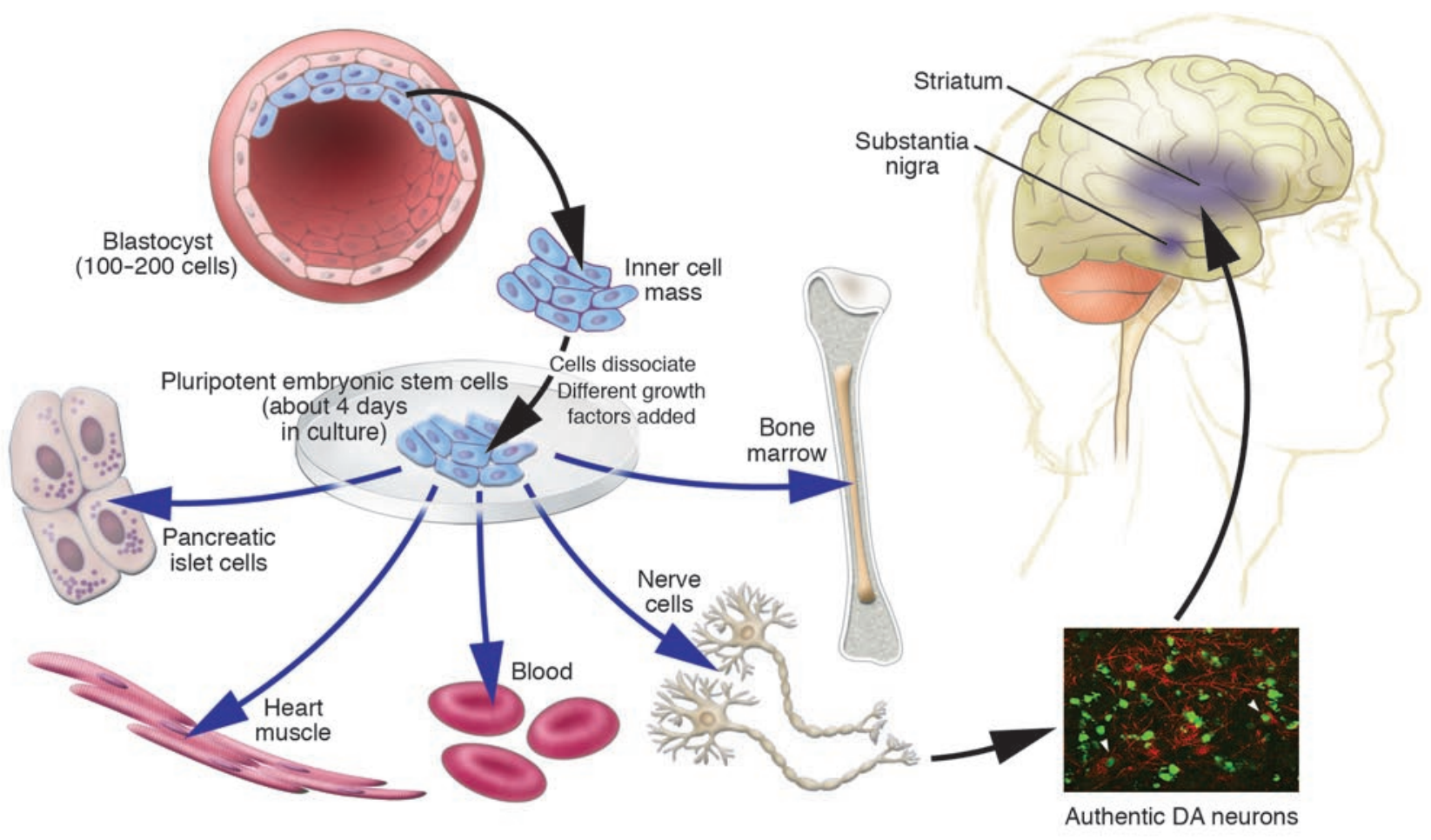

Figure 1

Pluripotent embryonic stem cells are obtained from the inner cell mass of the blastocyst stage of development. These cells have the potential to develop into any tissue type. A variety of different treatments or "cocktails" have been devised to coax these cells into developing into a neuronal lineage and then into authentic DA neurons. Green, BrdU; red, tyrosine hydroxylase-positive (TH-positive) DA neurons (8). These are then used for cell replacement therapy by transplantation into the area of the brain where DA nigrostriatal neurons have degenerated. To date, almost all fetal cell transplants have involved putting these cells into the striatum (which lies deep in the brain, below the shaded area in the figure) as have most experimental studies. However, it is still not clear that this is the best target area; it is also possible that it will be necessary to transplant the cells to multiple sites, including the substantia nigra. The major challenge at the current time appears to be getting transplanted DA embryonic stem cells to maintain their DA phenotype in large numbers and over a prolonged period of time.

receiving transplants, these movements persisted even after L-dopa was discontinued, raising serious safety concerns.

Why didn't this approach work? Theories range from poor graft survival to the possibility that low-grade inflammation interfered with graft function. But the reality is that we still don't know. Why is all this relevant to the use of stems cell to treat Parkinson disease? First, strategies used in fetal cell transplantation are essentially the same as those which will be applied with DA stem cells, but we are now in a quandary regarding this entire approach. A second hurdle relates to the vast technical barriers that are being encountered in the process of learning how to use stem cells to treat any human disease. With regard to Parkinson disease, the first task has been to create authentic DA cell lines that can be used to replace the missing neurons in the nigrostriatal system, and the second to get those cells to persist in vivo without forming tumors. While this has been an intensive area of research, there are only a limited number of successes so far, and these have been achieved primarily in rodents (4-7). For these reasons, the current report by Takagi and colleagues in this issue of the JCI is of great interest (8). These investigators have prepared what appear to be authentic DA neurons and used those cells to reverse parkinsonism in a primate model of the disease (Figure 1). This is important because treatment of 1-methyl-4phenyl-1,2,3,6-tetrahydropyridine-induced (MPTP-induced) parkinsonism in primates (the model used here) has proven highly predictive of new symptomatic approaches in the treatment of Parkinson disease. Yet we still have a long way to go.

\section{Challenges for the future}

While the observations in the current study (8) are encouraging, the number of surviving DA neurons was very low, with only $1 \%$ to $3 \%$ of the cells surviving - well below the estimated number of DA neurons that survived after fetal cell trans- plants, where figures hovered around 10\%. The explanation may lie in species differences and/or simple volumetric issues; however, based on what we have learned to date in human fetal cell trials, it may be necessary for far more DA neurons to survive, and, of course, the survival must be long lasting, an aspect of therapy that was not assessed in the current study. It is also important to note that, as the authors point out, dyskinesias were not observed in their monkeys. However, the authors do not present evidence that this species develops L-dopa-induced dyskinesias, and much longer-term follow-up may be needed since dyskinesias were typically not seen during the first year in human studies. It is good news that tumors were not observed, but this could also be related to the small number of surviving cells.

Keeping in mind these caveats, clearly the study reported here will advance research aimed at validating the use of stem cells to treat neurodegenerative disease. And 
this is most welcome, particularly for investigators working on strategies for cell replacement the United States, who must be feeling something of a déjà vu in face of yet another presidential moratorium, this time limiting the number of human stem cell lines that can be used for research and treatment. Ironically, this frustration recently led California voters to approve a $\$ 3$ billion initiative to fund stem cell research, which some have predicted will lead to a "gold rush" on stem cell research (9). Regardless of whether or not this proves to be the case, it can be hoped that this new initiative will serve as a beacon of hope for scientists and patients alike as we press ahead in this challenging area of science that appears to promise so much for the treatment of human diseases.

Address correspondence to: J. William Langston, The Parkinson's Institute, 1170 Morse Avenue, Sunnyvale, California 94089-1605, USA. Phone: (408) 734-2800; Fax: (408) 734-8522; E-mail: jwlangston@thepi.org.

\footnotetext{
1. Freed, C.R., et al. 2001. Transplantation of embryonic dopamine neurons for severe Parkinson's disease. N. Engl. J. Med. 344:710-719.

2. Olanow, C.W., et al. 2003. A double-blind controlled trial of bilateral fetal nigral transplantation in Parkinson's disease. Ann. Neurol. 54:403-414.

3. Kordower, J.H., and Sortwell, C.E. 2000. Neuropathology of fetal nigra transplants for Parkinson's disease. Prog. Brain Res. 127:333-344.
}

4. Studer, L., Tabar, V., and McKay, R.D. 1998. Transplantation of expanded mesencephalic precursors leads to recovery in parkinsonian rats. Nat. Neurosci. 1:290-295.

5. Isacson, O., et al. 2001. Cell implantation therapies for Parkinson's disease using neural stem, transgenic or xenogeneic donor cells. Parkinsonism Relat. Disord. 7:205-212.

6. Sanchez-Pernaute, R., Studer, L., Bankiewicz, K.S., Major, E.O., and McKay, R.D. 2001. In vitro generation and transplantation of precursor-derived human dopamine neurons. J. Neurosci. Res. 65:284-288.

7. Kim, J.H., et al. 2002. Dopamine neurons derived from embryonic stem cells function in an animal model of Parkinson's disease. Nature. 418:50-56.

8. Takagi, Y., et al. 2005. Dopaminergic neurons generated from monkey embryonic stem cells function in a Parkinson primate model. J. Clin. Invest. 115:102-109. doi:10.1172/JCI200521137.

9. Holden, C. 2004. U.S. science policy. California's Proposition 71 launches stem cell gold rush. Science. 306:1111.

\section{Immune complexes as therapy for autoimmunity}

\section{Raphael Clynes}

Department of Medicine and Microbiology, Columbia University, New York, New York, USA.

\begin{abstract}
For several decades, intravenous Ig has been used as treatment for a variety of immune-related diseases, including immune thrombocytopenic purpura (ITP), autoimmune neuropathies, systemic lupus erythematosus, myasthenia gravis, Guillain-Barré syndrome, skin blistering syndromes, and Kawasaki disease. Despite years of use, its mechanism of immunomodulation is still unclear. Recent studies using mouse models of ITP and arthritis, including one reported in this issue of the JCI (see the related article beginning on page 155), now provide some insights into this mechanism and the rationale for the development of Fc $\gamma$ receptor-targeted therapeutics.
\end{abstract}

\section{Fc receptors in the pathogenesis and treatment of ITP}

Intravenous Ig (IVIg) is remarkably effective in the treatment of immune thrombocytopenic purpura (ITP), with improved platelet counts seen in $80 \%$ of treated patients. ITP occurs in patients as the result of the generation of autoantibodies that bind to platelet surface antigens. These opsonized platelets are phagocytosed by Fc receptor-bearing splenic and hepatic macrophages (1). In the mouse, macrophage-mediated clearance occurs via activating $\mathrm{Fc}$ receptors, with complement-mediated uptake playing little or no role $(2,3)$. Thus, blockade of activating $\mathrm{Fc} \gamma$ receptors $(\mathrm{Fc} \gamma \mathrm{Rs})$ would be predicted to be an effec-

Nonstandard abbreviations used: $F_{c} \gamma \mathrm{R}, \mathrm{Fc} \gamma$ receptor; IC, immune complex; ITP, immune thrombocytopenic purpura; IVIg, intravenous Ig.

Conflict of interest: The author has declared that no conflict of interest exists.

Citation for this article: J. Clin. Invest. 115:25-27 (2005). doi:10.1172/JCI200523994. tive therapy in ITP. Indeed, this has proven to be a valid approach; antibodies that block FcyRIII have been shown to be effective in murine studies $(2,4)$ as well as in pilot clinical studies (5).

Although activating $F_{c}$ receptor blockade is an appealing mechanism, a second, unexpected FcyR-related pathway is clearly relevant to the therapeutic action of IVIg. It was recently shown (4) that the protective effect of IVIg is associated with upregulation of the inhibitory receptor Fc $\gamma$ RIIB on splenic macrophages and is abrogated in mice lacking Fc RIIB. Curiously, this effect is independent of SHIP and SHP-1 (6), the 2 downstream inhibitory phosphatases previously assumed to be responsible for the inhibitory signaling pathway. Redundant functions of SHIP and SHP-1 or other phosphatases downstream of Fc $\mathrm{RIIB}$ may be responsible (7), but as yet the FC $\gamma$ RIIB-mediated signal is unclear. Adding further to the mystery is the observation that 2 distinct macrophage populations are involved; IVIg protection requires CSF-1- dependent macrophages, whereas the macrophage responsible for Fc $\gamma$ RIII-mediated platelet clearance is CSF-1 independent (8). Thus, while other targets may prove effective in the treatment of immune complex-related (IC-related) autoimmunity $(9,10)$, at least 2 distinct $\mathrm{Fc} \gamma \mathrm{R}$ therapeutic approaches are tenable: direct blockade of the phagocytic Fc receptors and IVIg-triggered, Fc $\gamma$ RIIB-mediated inhibition (Figure 1).

\section{What is the active component of IVIg and intravenous anti-D?}

A related therapeutic, intravenous anti-D, has also been highly effective in ITP, but only in $\mathrm{Rh}^{+}$patients. The active component is clearly anti-D antibodies that generate large particulate ICs, namely opsonized rbcs, in $\mathrm{Rh}^{+}$ patients. In contrast, the active components in IVIg, a product obtained from sera pooled from thousands of donors, could conceivably include a variety of $\mathrm{Fc}$ receptor-binding ligands. In addition to the dominant species of monomeric IgG (which would bind FcRn and the high-affinity $\mathrm{Fc} \gamma \mathrm{RI}$ ), multiple types of ICs, which bind all $F_{C}$ receptors, are likely to form in vivo after the administration of IVIg. These complexes of varying valencies include cell-associated and soluble host antigens bound by donor natural antibodies as well as dimers and aggregated Igs formed in the IVIg product itself. Using mimetic modeling studies, Siragam et al. (11) suggest that the 2 therapeutics IVIg and anti-D have 